\title{
Production of Bleached Cement
}

\author{
D. Mishin ${ }^{(凶)}$ and S. Kovalev \\ Department of Technology of Cement and Composite Materials, \\ Institute of Chemical Technology, Belgorod State Technological University \\ named after V.G. Shukhov, Belgorod, Russia \\ mishinda.xtsm@yandex.ru
}

\begin{abstract}
The present paper studies a new method of bleaching that allows extending the range of raw materials for white cement. This paper investigates the separate introduction of mineralizers into raw slurry of CJSC Belgorod Cement plant containing $2.78 \%$ of $\mathrm{Fe}_{2} \mathrm{O}_{3}$. The separate introduction of mineralizers provides bleaching effect and complete consumption of free calcium oxide at the temperature of $1250{ }^{\circ} \mathrm{C}$. The bleaching is caused by the reduced content and changed composition of ferroaluminate phase.
\end{abstract}

Keywords: Clinker bleaching - White cement - Separate introduction · $\mathrm{Na}_{2} \mathrm{CO}_{3} \cdot \mathrm{CaF}_{2} \cdot$ Mineralizers

\section{Introduction}

Currently, white cement is one of the most demanded building materials due to its wide building and technological properties. The demand for this cement grows with the rate of city development. However, the development of white cement industry is limited by strict requirements to the quality of raw materials. To produce cement of graded whiteness, the content of iron oxide in the clinker should not exceed $0.5 \%$ (Zubekhin et al. 2004). The number of stock deposits that can provide such content of iron oxide in clinker is relatively low and will gradually decrease with their depletion.

Thus, the development of new technologies extending the range of raw material sources for white cement by involving components with higher iron content becomes very urgent.

\section{Methods and Approaches}

Materials and Methods. The raw mixture with high content of $\mathrm{Fe}_{2} \mathrm{O}_{3}$ was represented by dried slurry of CJSC Belgorod Cement plant (Table 1) with the following module characteristics: $\mathrm{LSF}=0.91 ; \mathrm{n}=2.23 ; \mathrm{p}=1.29$.

The raw mixture was doped by mineralizers $\mathrm{Na}_{2} \mathrm{CO}_{3}, \mathrm{CaF}_{2}$ and $2 \mathrm{C}_{2} \mathrm{~S} \cdot \mathrm{CaF}_{2}$ calculated as ignition basis over $100 \%$ : The final mixture contained $3.5 \%$ of sodium carbonate as $\mathrm{R}_{2} \mathrm{O}, 1.5 \%$ of calcium fluoride and $8.11 \%$ of synthesized $2 \mathrm{C}_{2} \mathrm{~S} \cdot \mathrm{CaF}_{2}(1.5 \%$ if expressed as $\mathrm{CaF}_{2}$ ). The mineralizers were introduced separately (Mishin et al. 2016). 
Table 1. Chemical composition of slurry of CJSC Belgorod Cement plant [\%]

\begin{tabular}{l|l|l|l|l|l|l|l|l|l}
\hline Loss on ignition & $\mathrm{SiO}_{2}$ & $\mathrm{Al}_{2} \mathrm{O}_{3}$ & $\mathrm{Fe}_{2} \mathrm{O}_{3}$ & $\mathrm{CaO}$ & $\mathrm{MgO}$ & $\mathrm{K}_{2} \mathrm{O}$ & $\mathrm{Na}_{2} \mathrm{O}$ & $\mathrm{SO}_{3}$ & other \\
\hline 34.8 & 14.23 & 3.59 & 2.78 & 43.12 & 0.6 & 0.4 & 0.11 & 0.09 & 0.37 \\
\hline
\end{tabular}

The effect of mineralizers on the phase composition of the clinker was established using XRD analysis using ARL ${ }^{\text {TM }}$ X'TRA Powder Diffractometer (Switzerland).

The completion of clinker formation process was assessed by the content of free calcium oxide. The content of $\mathrm{CaO}_{\text {free }}$ was determined by ethyl-glycerate method (Boutt and Timashev 1973).

The whiteness grade (brightness coefficient) of the clinker was determined by FB-2 reflection meter using reference polished plate of barium sulphate.

\section{Results and Discussion}

The implementation of separate introduction of mineralizers leads to bleaching of the samples at the temperature of $1250-1300{ }^{\circ} \mathrm{C}$ (Fig. 1(1)). The increase of the burning temperature from 1250 to $1300{ }^{\circ} \mathrm{C}$ causes gradual return of clinker color to typical black (Fig. 1(1), (2) and (3)).
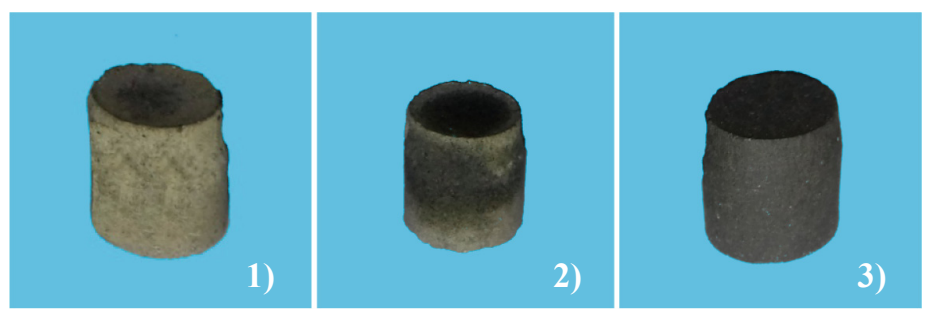

Fig. 1. Appearance of clinker samples produced by separate introduction at burning temperature of: (1) $1250{ }^{\circ} \mathrm{C}$; (2) $1275{ }^{\circ} \mathrm{C}$; (3) $1300{ }^{\circ} \mathrm{C}$.

In this temperature interval, complete consumption of free calcium oxide is observed, which indicates the completion of clinker formation processes (Table 2).

Table 2. Characteristics of clinker samples produced by separate introduction of $2 \mathrm{C}_{2} \mathrm{~S} \cdot \mathrm{CaF}_{2}$ mineralizer

\begin{tabular}{l|l|l|l|l|l}
\hline Burning temperature $\left[{ }^{\circ} \mathrm{C}\right]$ & 1250 & 1250 & 1275 & 1300 & $1400^{*}$ \\
\hline Cooling method & (water) & (air) & (air) & (air) & (air) \\
\hline Content of $\mathrm{CaO}_{\text {free }}[\%]$ & 0.55 & 0.5 & 0.3 & 0.31 & 0.10 \\
\hline Brightness coefficient [\%] & 46 & 41 & 37.5 & 30 & 31 \\
\hline
\end{tabular}

* common plant clinker 


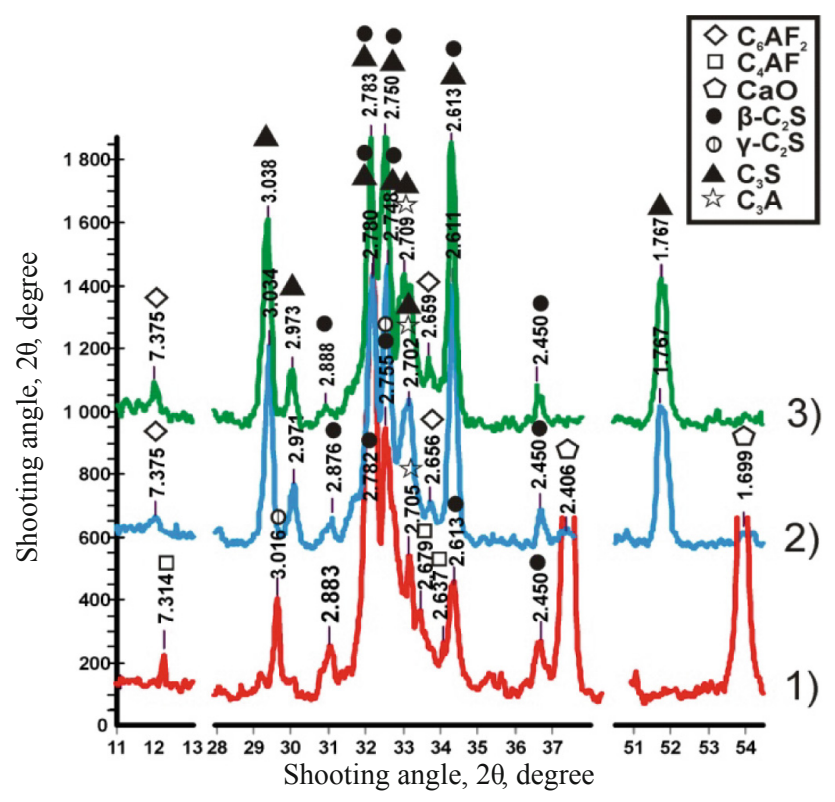

Fig. 2. Phase composition of clinker samples: (1) no additives at $1250{ }^{\circ} \mathrm{C}$; produced by separate introduction at: (2) $1250{ }^{\circ} \mathrm{C}$; (3) $1300{ }^{\circ} \mathrm{C}$.

According to the phase composition analysis, at the burning temperature of $1250{ }^{\circ} \mathrm{C}$ (Figs. 2(1), (2)), in the samples produced by separate introduction, the composition of ferroaluminate phase $\mathrm{C}_{4} \mathrm{AF}$ (d, $\AA$ : $7.314 ; 2.679 ; 2.637$ ) shifts into the region of compositions with a higher iron content and approaches that of $\mathrm{C}_{6} \mathrm{AF}_{2}(\mathrm{~d}, \AA$ : $7.375 ; 2.656)$. The intensity of reflections of the ferroaluminate phase decreases, which tells about the decrease in its content in the clinker. Ferroaluminate phase is the most coloring among the clinker components (Zubekhin et al. 2004). In this connection, the decreased amount of ferroaluminate phase leads to increased brightness coefficient of the clinker.

The increased burning temperature up to $1300{ }^{\circ} \mathrm{C}$ (Fig. 2(3)) causes increased intensity of ferroaluminate phase reflections (d, $\AA$ : $7.375 ; 2.659)$, which witnesses its increased content in the clinker. As a result, the brightness coefficient of the clinker reduces from $41 \%$ down to $30 \%$.

\section{Conclusions}

The separate introduction of mineralizer allows bleaching the clinker with the iron oxide content of more than $0.5 \%$. With the iron oxide content in raw mixture of $2.78 \%$, the brightness coefficient increases from $31 \%$ up to $46 \%$.

The increase in the brightness coefficient is connected with decreased content of calcium ferroaluminate phases in the clinker: $\mathrm{C}_{4} \mathrm{AF}, \mathrm{C}_{6} \mathrm{AF}_{2}$. 
The implementation of separate introduction of mineralizer will allow extending the range of sources for white cement production involving raw components with increased iron content.

The separate introduction of mineralizer in the presence of increased iron oxide content allows achieving complete consumption of free calcium oxide at $1250{ }^{\circ} \mathrm{C}$.

Acknowledgements. The work is realized in the framework of the Program of flagship university development on the base of Belgorod State Technological University named after V.G. Shoukhov, using equipment of High Technology Center at BSTU named after V.G. Shoukhov.

\section{References}

Boutt YM, Timashev VV (1973) Practical guide on chemical technologies of binders: guide. Higher school, Moscow, 504 p. (in Russian)

Mishin DA, Kovalev SV, Chekulaev VG (2016) Reason for reduced efficacy of mineralizers for burning Portland cement clinker. Bulletin of BSTU n.a. V.G. Shoukhov, no 5, p 161-166 (in Russian)

Zubekhin AP, Golovanova SP, Kirsanov PV (2004) White Portland cement. Zubekhin AP (ed) J. "Bulletin of HEIs North-Caucasus region", Rostov on Don, 264 p (in Russian)

Open Access This chapter is licensed under the terms of the Creative Commons Attribution 4.0 International License (http://creativecommons.org/licenses/by/4.0/), which permits use, sharing, adaptation, distribution and reproduction in any medium or format, as long as you give appropriate credit to the original author(s) and the source, provide a link to the Creative Commons license and indicate if changes were made.

The images or other third party material in this chapter are included in the chapter's Creative Commons license, unless indicated otherwise in a credit line to the material. If material is not included in the chapter's Creative Commons license and your intended use is not permitted by statutory regulation or exceeds the permitted use, you will need to obtain permission directly from the copyright holder.

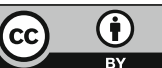

